\title{
Effect of Ventilatory Variability on Occurrence of Central Apneas
}

\author{
Stephane Delisle RRT MSc PhD FCSRT, Nicolas Terzi MD PhD, Paul Ouellet RRT, \\ Patrick Bellemare MD, Jean-Pierre Tétrault MD MSc, and Pierre Arsenault MD PhD
}

\begin{abstract}
OBJECTIVE: To compare the influence of 2 ventilation strategies on the occurrence of central apneas. METHODS: This was a prospective, comparative, crossover study with 14 unsedated subjects undergoing weaning from mechanical ventilation in the medical ICU of Hôpital du SacréCœur, Montréal, Québec, Canada. The subjects were ventilated alternately in neurally adjusted ventilatory assist (NAVA) and pressure support ventilation (PSV) modes. Inspiratory flow/time and pressure/time waveforms and diaphragmatic electrical activity were used to detect central apneas. Ventilatory variability and breathing pattern were evaluated in both modes. Breathing patterns just before central apneas, and associations between apneas and sleep patterns (electroencephalogram) were studied. RESULTS: Switching from PSV to NAVA did not change mean minute ventilation, tidal volume, or breathing frequency. However, tidal volume variability, defined as the coefficient of variability (standard error/mean), was significantly greater with NAVA than with PSV $(17.2 \pm 8$ vs $10.3 \pm 4, P=.045$ ). NAVA induced a greater decrease in central apneas, compared to PSV (to 0 with NAVA vs $10.5 \pm 11$ with PSV, $P=.005$ ). Central apneas during PSV were detected only during non-rapid-eye-movement sleep. CONCLUSIONS: NAVA was associated with increased ventilatory variability, compared to constant-level PSV. With NAVA the absence of over-assistance during sleep coincided with absence of central apneas, suggesting that load capacity and/or neuromechanical coupling were improved by NAVA and that this improvement decreased or abolished central apneas. Key words: mechanical ventilation; central apnea; ventilation mode; neurally adjusted ventilatory assist; pressure support; sleep patterns. [Respir Care 2013;58(5):745-753. (C) 2013 Daedalus Enterprises]
\end{abstract}

\section{Introduction}

Pressure support ventilation (PSV) is widely used, most notably during weaning off mechanical ventilation, but

\footnotetext{
Drs Delisle and Bellemare are affiliated with the Service des Soins Intensifs, Hôpital du Sacré-Cœur de Montréal, Montréal, Québec, Canada. Dr Delisle is also affiliated with the Département de Médecine Familiale et d'Urgence, Université de Montréal, Montréal, Québec, Canada; and with the Programme des Sciences Cliniques, Université de Sherbrooke, Sherbrooke, Québec, Canada. Dr Terzi is affiliated with the Service de Réanimation Médicale, Centre Hospitalier Universitaire Caen; with Institut National de la Santé et de la Recherche Médicale, U1075; and with the Universite de Caen, Caen, France. Mr Ouellet is affiliated with the Département de Chirurgie; Dr Tétrault is affiliated with the Département d'Anesthésie; and Dr Arsenault is affiliated with the Département de Médecine Familiale, Centre Hospitalier Universitaire de Sherbrooke, Sherbrooke, Québec, Canada. Mr Ouellet is also affiliated with the Critical Care Department, Vitalite 5 Health Network, Edmundston, New Brunswick, Canada; and with the Programme des Sciences Cliniques, Université de Sherbrooke, Sherbrooke, Québec, Canada.
}

may be associated with central apneas and intermittent breathing. ${ }^{1}$ During sleep in PSV mode, inspiratory efforts are constant but tidal volume $\left(\mathrm{V}_{\mathrm{T}}\right)$ oscillates, intermittently decreasing the $\mathrm{P}_{\mathrm{aCO}}$ level below the apneic threshold, which is not very different from the $\mathrm{P}_{\mathrm{aCO}}$ value in eupnea. ${ }^{2}$ The apneic $\mathrm{P}_{\mathrm{aCO}}$ threshold is physiologically lower during stage 1 sleep than during wakefulness. ${ }^{2,3}$ Studies show that patients who shift repeatedly between sleep stages exhibit increased sensitivity to central apneas. ${ }^{2,3}$

\footnotetext{
Dr Delisle has disclosed a relationship with Fisher \& Paykel. The other authors have disclosed no conflicts of interest.

Correspondence: Stephane Delisle RRT MSc PhD FCSRT, Service des Soins Intensifs, Hôpital du Sacré-Cœur de Montréal, 5400 Boulevard Gouin Ouest, Montréal, Québec H4J 1C5 Canada. E-mail: sdelisle@hotmail.com.
}

DOI: $10.4187 /$ respcare. 01456 
Central apneas are associated with arousals related to the increase in respiratory effort often seen after apneas. ${ }^{4,5}$ Severe sleep disruption has been reported in patients with Cheyne-Stokes respiration. The sleep disruption was due to repeated arousals during the hyperpneic phase of CheyneStokes respiration, which accounted for two thirds of all arousals. ${ }^{6,7}$ In theory, arousals are responsible for a sympathetic response manifesting as tachycardia, hypertension, and increased myocardial oxygen consumption. ${ }^{8}$ In mechanically ventilated patients, additional factors that may induce arousals include the audio alarm triggered by low minute ventilation $\left(\dot{\mathrm{V}}_{\mathrm{E}}\right)$ and initiation of the apnea backup mode. All these factors must be considered when choosing ventilation settings.

\section{See the Related Editorial on Page 884}

Excessive pressure support during sleep may increase the likelihood of periodic breathing, although $\mathrm{CO}_{2}$ sensitivity is not modified, since $\dot{\mathrm{V}}_{\mathrm{E}}$ increases in response to $\mathrm{P}_{\mathrm{aCO}_{2}}$ elevation. ${ }^{9}$ However, it does not appear possible to determine the difference between the actual $\mathrm{P}_{\mathrm{aCO}}$ and the $\mathrm{P}_{\mathrm{aCO}_{2}}$ apneic threshold (fraction of expired $\mathrm{CO}_{2}-\mathrm{P}_{\mathrm{aCO}_{2}}$ ) in individual patients receiving mechanical ventilation, without performing individual titration through trial and error.

To improve the match between the patient's needs and the assistance delivered by the ventilator, manufacturers have developed several new modes of mechanical ventilation, ${ }^{10}$ including proportional assist ventilation and neurally adjusted ventilatory assist (NAVA). NAVA is an assist mode that delivers a pressure proportional to the integral of the electrical activity of the diaphragm (EAdi). ${ }^{11}$ Therefore, the pressure level is determined by the neural output of the patient's central respiratory command, which would be expected to prevent over-assistance. ${ }^{12-15}$ Moreover, recent studies suggest that NAVA may allow a high level of breathing pattern variability. ${ }^{16-17}$ Avoiding overassistance and delivering proportional assistance would be expected to limit apneas, although ventilation varies less during the night than during the day.

The objective of the prospective study reported here was to compare the effects of NAVA and PSV on the occurrence of central apneas during weaning.

\section{Methods}

The ethics committee of Hôpital du Sacré-Cœur, Montréal, Québec, Canada, approved the study, and subjects or their surrogates gave their informed consent.

\section{Study Population}

This study was performed in the same population as a previous study from our group on NAVA and sleep. ${ }^{18}$ We

\section{QUICK LOOK}

\section{Current knowledge}

During weaning from mechanical ventilation, excessive pressure during pressure support ventilation is associated with intermittent apnea, because $\mathrm{P}_{\mathrm{aCO}}$ is driven below the apneic threshold. During sleep this intermittent breathing pattern is associated with fragmented sleep.

\section{What this paper contributes to our knowledge}

The use of neurally adjusted ventilatory assist (NAVA) ventilation reduces the incidence of central apneas and increases the variability in tidal volume, compared to excessive pressure with pressure support ventilation. For the mean minute ventilation and respiratory rate, there was no difference between the 2 techniques.

conducted a prospective, interventional, crossover study in a 22-bed medical ICU at Hôpital du Sacré-Cœur over a 12 -month period. Inclusion criteria were invasive mechanical ventilation, normal consciousness, absence of sedatives and opiates for $\geq 24 \mathrm{~h}$, and PSV with an $\mathrm{F}_{\mathrm{IO}_{2}}$ below 0.60 and a PEEP of $5 \mathrm{~cm} \mathrm{H} \mathrm{O}$ to achieve an $\mathrm{S}_{\mathrm{pO}_{2}}$ of at least $90 \%$. Exclusion criteria were presence of a central nervous system disorder, Glasgow Coma Scale score $<11$, hemodynamic instability, renal and/or hepatic insufficiency, ongoing sepsis, history of esophageal varices or gastroesophageal bleeding in the past 30 days, and history of gastrointestinal symptoms such as vomiting.

\section{Ventilation Methods}

All subjects were ventilated through an endotracheal or tracheostomy tube. Subjects meeting the inclusion criteria were connected to a ventilator capable of delivering both PSV and NAVA (Servo-i, Maquet Critical Care, Sölna, Sweden). As previously described, ${ }^{19}$ EAdi was recorded using a 16 French gastric catheter equipped with electrodes (EAdi catheter, Maquet Critical Care, Sölna, Sweden), whose correct position was checked using the "EAdi catheter positioning" ventilator function. Humidification was provided by a heat and moisture exchanger in all subjects. End-tidal $\mathrm{CO}_{2}\left(\mathrm{P}_{\mathrm{ETCO}_{2}}\right)$ was monitored with the Servo-i volumetric $\mathrm{CO}_{2}$ module.

PSV and NAVA were delivered in random order, determined using a closed-envelope technique. Each mode was delivered for 4 periods of 4 hours: 2 during the day (7:00 to 11:00 AM and 12:00 to 4:00 PM) and 2 at night (10:00 PM to 2:00 AM and 3:00 to 7:00 AM). To prevent possible data contamination from the previous mode of 

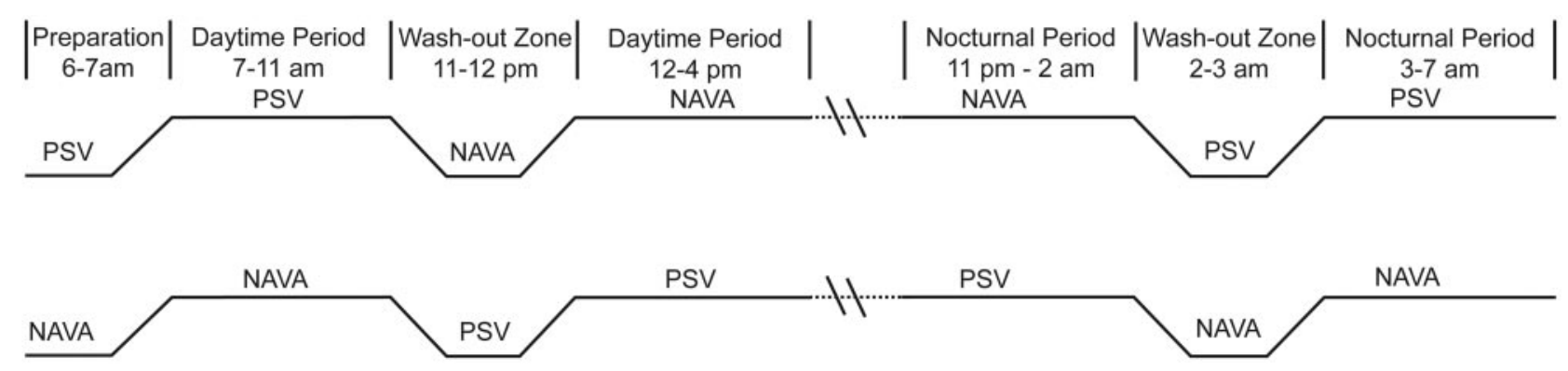

Fig. 1. Study protocol. Each recording lasted 4 hours, and 4 recordings were obtained with each subject, for a total of 24 consecutive hours. PSV $=$ pressure support ventilation. NAVA = neurally adjusted ventilatory assist.

ventilation, data acquisition was delayed for 1 hour after each ventilator setting change (Fig. 1).

Inspiratory pressure support was titrated to obtain a $\mathrm{V}_{\mathrm{T}}$ of $8 \mathrm{~mL} / \mathrm{kg}$ of predicted body weight during active inspiration, without exceeding $20 \mathrm{~cm} \mathrm{H}_{2} \mathrm{O}$ of pressure support and a breathing frequency of $<35$ breaths/min. Flowtrigger sensitivity was set as low as possible (1-2 L/min) without inducing auto-triggering; cycling-off occurred when the inspiratory flow fell below $25 \%$ of the peak inspiratory flow. During PSV the ventilator function "NAVA Preview" was used to estimate the NAVA level required to achieve the same peak inspiratory pressure. After switching to NAVA, the settings were gradually adjusted to deliver the same assist level (peak pressure) and external PEEP as used previously with PSV. With NAVA the EAdi inspiratory trigger was at the lowest setting $(0.5 \mu \mathrm{V})$. EAdi was recorded with both ventilation modes and used to evaluate patient-ventilator synchrony.

The backup apnea ventilation delay was set at $15 \mathrm{sec}-$ onds, so that apneas lasting 10 seconds or more could be identified and their impact on sleep architecture (arousals) assessed.

\section{Sleep Patterns}

The electroencephalogram was recorded using standard electrode positions (left frontal/right auricular reference [F3/A2], right frontal/left auricular reference [F4-A1], left central/right auricular reference [C3/A2], right central/left auricular reference [C4/A1], left occipital/right auricular reference [O1/A2], and right occipital/left auricular reference [O2/A1] in the international 10-20 system for electrode placement). ${ }^{20}$ The standard reference was the left mastoid lead. ${ }^{20}$ Two electrooculogram and 3 chin electromyogram leads were used to score rapid-eye-movement (REM) and non-REM sleep. The electroencephalogram, right and left electrooculograms, and submental electromyogram signals were amplified and recorded in the data acquisition system (Alice 5 polysomnography system using Alice Sleepware 2.5 software, Respironics, Murrysville, Pennsylvania).

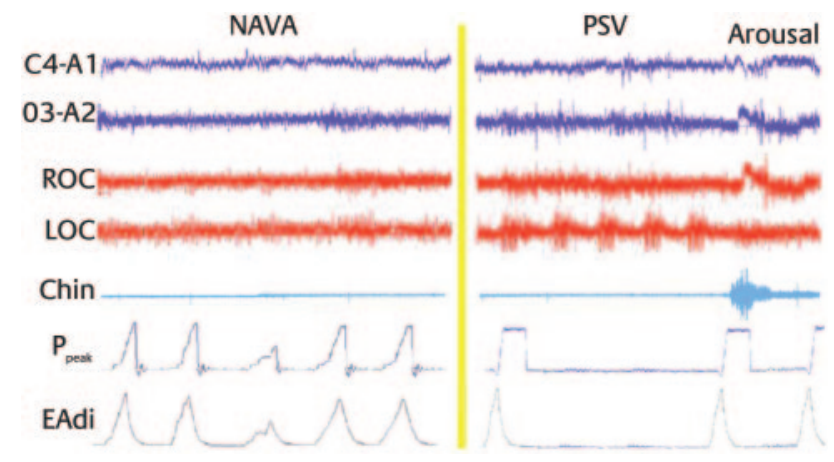

Fig. 2. Polysomnography tracings with neurally adjusted ventilatory assist (NAVA) and pressure support ventilation (PSV) in a representative subject. C4-A1 and O3-A2 are the electroencephalogram readings. $\mathrm{ROC}$ and $\mathrm{LOC}$ are the electrooculogram readings. Chin is the electromyogram reading. $P_{\text {peak }}$ is the peak airway pressure. EAdi is the electrical activity of the diaphragm reading.

Sleep recordings were scored manually by a pulmonologist who was blinded to the study data and used Rechtschaffen and Kales criteria for sleep stages, ${ }^{21}$ and American Sleep Disorder Association criteria for arousals and awakenings. ${ }^{22,23}$ Central apneas were diagnosed according to international recommendations, ${ }^{23}$ as absence of breathing and respiratory effort for at least 10 seconds (Fig. 2). Arousals and awakening were classified as apnearelated if they occurred within 3 breaths and/or 15 seconds of the end of an apnea. ${ }^{24,25}$

\section{Data Acquisition and Analysis}

Flow and pressure signals were acquired at a sampling rate of $100 \mathrm{~Hz}$. Signals from each electrode pair were differentially amplified, digitized, and processed online, using previously described filters and algorithms. ${ }^{26-28}$ Changes in diaphragm position along the array were accounted for using the cross-correlation technique, ${ }^{29,30}$ and diaphragm-to-electrode distance filtering was minimized using the double-subtraction technique. ${ }^{31}$ The root mean square was calculated for the subtracted signal and the 
signal obtained from the electrode pair on the diaphragm, and these values were summed every $16 \mathrm{~ms}$ to quantify EAdi. Signal segments with residual disturbances due to cardiac electric activity or common mode signals were identified using specific detectors and replaced by the previously accepted value. This processed EAdi signal was used to control the ventilator during NAVA and was simultaneously acquired at a sampling rate of $2,000 \mathrm{~Hz}$.

EAdi was obtained from the ventilator through an RS232 interface, at a sampling rate of $100 \mathrm{~Hz}$, and recorded using dedicated software (Nava Tracker 2.0, Maquet Critical Care, Sölna, Sweden). The input was analyzed using software (Analysis 1.0, Maquet Critical Care, Sölna, Sweden, and a customized version of Excel, Microsoft, Redmond, Washington).

The peak of rectified and integrated EAdi swings (peak EAdi) was measured. From the flow signal we obtained the ventilator frequency (f-flow), flow-based inspiratory time, and flow-based expiratory time. To evaluate breathing pattern variability during the different sleep stages with each mode, we calculated the coefficient of variability (defined as the standard error/mean ratio $\times 100$ ) for $\mathrm{V}_{\mathrm{T}}$, breathing frequency, and peak EAdi. ${ }^{32,33}$

\section{Statistics}

The statistical analysis was performed using statistical software (SPSS 17.0, SPSS, Chicago, Illinois). Continuous variables are described as mean $\pm \mathrm{SD}$. Data were compared using the general linear model for repeated measures. Given the small sample size, a nonparametric test was used to compare variables; we chose the Wilcoxon test for paired samples. Two-tailed $P$ values smaller than .05 were considered significant. Variability data were compared using analysis of variance for repeated measures.

\section{Results}

\section{Study Population}

We included 14 subjects, whose main characteristics at admission are reported in Table 1. Mechanical ventilation was required for acute respiratory failure in 10 subjects, postoperative cardiac complications in 3 subjects, and septic shock in 1 subject. Mean PSV level was $15 \pm 5 \mathrm{~cm} \mathrm{H}_{2} \mathrm{O}$, and mean NAVA level was $1.6 \pm 1.4 \mathrm{~cm} \mathrm{H}_{2} \mathrm{O} / \mu \mathrm{V}$. PEEP was kept at $5 \mathrm{~cm} \mathrm{H}_{2} \mathrm{O}$ in all subjects with both ventilation modes.

\section{Breathing Pattern}

Mean total sleep time was $537 \pm 193$ min. Mean sleep efficiency (the percentage of sleep during the study) was
Table 1. Subjects

\begin{tabular}{lc}
\hline \hline Male/female & $8 / 6$ \\
Age, mean \pm SD y & $64 \pm 11$ \\
SAPS II at ICU admission, mean \pm SD & $46 \pm 12$ \\
Duration of mechanical ventilation, mean \pm SD d & $17 \pm 9$ \\
Tracheotomy, \% & 14 \\
Cause for initial mechanical ventilation, $\%$ & \\
$\quad$ Acute respiratory failure & 71.5 \\
Postoperative complication & 21.5 \\
Septic shock & 7 \\
Underlying antecedents, \% & \\
Chronic heart failure & 57 \\
Atherosclerotic heart disease & 50 \\
COPD & 0 \\
Bronchiectasis & 7 \\
Hypertension & 71 \\
Diabetes & 36 \\
\hline SAPS = Simplified Acute Physiology Score & \\
\hline
\end{tabular}

$56 \pm 20 \%$. Table 2 reports the main breathing pattern data. Mean $\dot{\mathrm{V}}_{\mathrm{E}}$ did not differ significantly between PSV and NAVA: $9.6 \pm 1.8 \mathrm{~L} / \mathrm{min}$ and $9.3 \pm 1.8 \mathrm{~L} / \mathrm{min}$, respectively $(P=.51)$. Mean breathing frequency was $17 \pm 4.6$ breaths $/ \mathrm{min}$ with PSV, and $18 \pm 5.7$ breaths $/ \mathrm{min}$ with NAVA $(P=.14)$. The mean $\dot{\mathrm{V}}_{\mathrm{E}}, \mathrm{V}_{\mathrm{T}}$, and breathing frequency did not differ significantly between the 2 ventilation modes. $\mathrm{P}_{\mathrm{ETCO}_{2}}$ was not significantly different between the 2 modes during any of the sleep stages.

$\mathrm{V}_{\mathrm{T}}$ differed significantly between the 2 ventilation modes during sleep stage 3-4 (mean $391 \pm 57 \mathrm{~mL}$ with NAVA and $435 \pm 64 \mathrm{~mL}$ with PSV, $P=.005)$ and during REM sleep (mean $360 \pm 54 \mathrm{~mL}$ with NAVA and $415 \pm 61 \mathrm{~mL}$ with PSV, $P=.008$, see Table 2). During PSV, $\mathrm{V}_{\mathrm{T}}$ did not vary significantly between wakefulness $(429 \pm 65 \mathrm{~mL})$ and REM sleep $(415 \pm 61 \mathrm{~mL})(P=.08)$. However, with NAVA, $V_{T}$ was significantly greater during wakefulness $(419 \pm 63 \mathrm{~mL})$ than during REM sleep $(360 \pm 54 \mathrm{~mL})$ $(P=.001) . \mathrm{V}_{\mathrm{T}}$ differed significantly between stage 1 and REM sleep with both modes (NAVA $431 \pm 69 \mathrm{~mL}$ vs $360 \pm 54 \mathrm{~mL}$, respectively, $P=.001$, PSV $442 \pm 61 \mathrm{~mL}$ vs $415 \pm 61 \mathrm{~mL}$, respectively, $P=.001$, see Table 2 ).

Mean breathing frequency during non-REM sleep did not differ significantly between the 2 ventilation modes. During REM sleep, in contrast, mean breathing frequency was significantly higher with NAVA than with PSV (15 \pm 3 breaths/min and $13 \pm 2$ breaths/min, respectively, $P=.004)$. During wakefulness the mean breathing frequency was also significantly higher with NAVA (20 \pm 4 breaths/min and $18 \pm 3$ breaths/min, respectively, $P=.005$, see Table 2).

Table 3 shows the oscillatory behavior of $\mathrm{V}_{\mathrm{T}}$, breathing frequency, $\dot{\mathrm{V}}_{\mathrm{E}}$, and $\mathrm{P}_{\mathrm{ETCO}}$ during sleep stages 2 and 3-4 with PSV. 
Table 2. $\quad \mathrm{V}_{\mathrm{T}}$, Breathing Frequency, Apneas per Hour, and $\mathrm{P}_{\mathrm{ETCO}_{2}}$ While Awake and Asleep

\begin{tabular}{|c|c|c|c|}
\hline & PSV & NAVA & $P$ \\
\hline \multicolumn{4}{|l|}{ Awake } \\
\hline $\mathrm{V}_{\mathrm{T}}, \mathrm{mL}$ & $429 \pm 65$ & $419 \pm 63$ & .49 \\
\hline $\mathrm{f}$, breaths/min & $18 \pm 3$ & $20 \pm 4$ & .005 \\
\hline Apneas/h & 0 & 0 & $>.99$ \\
\hline $\mathrm{P}_{\mathrm{ETCO}_{2}}, \mathrm{~mm} \mathrm{Hg}$ & $37.8 \pm 3.1$ & $36.9 \pm 3.4$ & .51 \\
\hline \multicolumn{4}{|l|}{ Sleep stage 1} \\
\hline $\mathrm{V}_{\mathrm{T}}, \mathrm{mL}$ & $442 \pm 61$ & $431 \pm 69$ & .30 \\
\hline $\mathrm{f}$, breaths $/ \mathrm{min}$ & $17 \pm 3$ & $17 \pm 4$ & .26 \\
\hline Apneas/h & $1.4 \pm 1$ & 0 & .003 \\
\hline $\mathrm{P}_{\mathrm{ETCO}_{2}}, \mathrm{~mm} \mathrm{Hg}$ & $36.8 \pm 4.7$ & $37.6 \pm 5.4$ & .80 \\
\hline \multicolumn{4}{|l|}{ Sleep stage 2} \\
\hline $\mathrm{V}_{\mathrm{T}}, \mathrm{mL}$ & $440 \pm 63$ & $426 \pm 70$ & .27 \\
\hline $\mathrm{f}$, breaths/min & $17 \pm 3$ & $18 \pm 4$ & .12 \\
\hline Apneas/h & $4.4 \pm 4$ & 0 & .02 \\
\hline $\mathrm{P}_{\mathrm{ETCO}_{2}}, \mathrm{~mm} \mathrm{Hg}$ & $36.3 \pm 6.2$ & $37.4 \pm 5.2$ & .53 \\
\hline \multicolumn{4}{|l|}{ Sleep stage $3-4$} \\
\hline $\mathrm{V}_{\mathrm{T}}, \mathrm{mL}$ & $435 \pm 64$ & $391 \pm 57$ & .005 \\
\hline $\mathrm{f}$, breaths/min & $13 \pm 3$ & $14 \pm 3$ & .13 \\
\hline Apneas/h & $4.7 \pm 6$ & 0 & .007 \\
\hline $\mathrm{P}_{\mathrm{ETCO}_{2}}, \mathrm{~mm} \mathrm{Hg}$ & $38.8 \pm 6.3$ & $39.2 \pm 5.8$ & .25 \\
\hline \multicolumn{4}{|c|}{ Rapid eye movement sleep } \\
\hline $\mathrm{V}_{\mathrm{T}}, \mathrm{mL}$ & $415 \pm 61$ & $360 \pm 54$ & .008 \\
\hline $\mathrm{f}$, breaths/min & $13 \pm 2$ & $15 \pm 3$ & .004 \\
\hline Apneas/h & 0 & 0 & $>.99$ \\
\hline $\mathrm{P}_{\mathrm{ETCO}_{2}}, \mathrm{~mm} \mathrm{Hg}$ & $39.6 \pm 5.3$ & $39.5 \pm 5.4$ & .50 \\
\hline \multicolumn{4}{|l|}{$\begin{array}{l}\text { Values are mean } \pm S D \\
V_{T}=\text { tidal volume } \\
f=\text { breathing frequency }\end{array}$} \\
\hline \multicolumn{4}{|c|}{$\begin{array}{l}\mathrm{P}_{\mathrm{ETCO}_{2}}=\text { end-tidal } \mathrm{P}_{\mathrm{CO}_{2}} \\
\mathrm{PSV}=\text { pressure support ventilation }\end{array}$} \\
\hline
\end{tabular}

\section{Apneas}

Sleep apnea occurred in 10 subjects, all of whom had either COPD or chronic heart failure, 2 known risk factors for central apneas. Moreover, these subjects experienced hyperventilation during sleep, which preceded the central apneas. Table 3 reports the mean number of sleep apneas per hour of sleep in the 10 subjects with sleep apnea. The mean sleep apnea index (number of apneas per hour of sleep) was $10.5 \pm 11$ during PSV and 0 during NAVA $(P=.005)$. During PSV, central apneas occurred only during non-REM sleep. All central apneas were associated with micro-arousals. During the second preceding the detection of central apneas, $\mathrm{V}_{\mathrm{T}}$ and $\dot{\mathrm{V}}_{\mathrm{E}}$ increased suddenly, while breathing frequency and $\mathrm{P}_{\mathrm{ETCO}_{2}}$ decreased (see Table 3$)$.

\section{Variability of Ventilation}

Table 4 reports the coefficient of variability values for $\mathrm{V}_{\mathrm{T}}$, f-flow, and peak EAdi. $\mathrm{V}_{\mathrm{T}}$ variability was greater with
Table 3. Oscillatory Behavior of $\mathrm{V}_{\mathrm{T}}$, Breathing Frequency, $\dot{\mathrm{V}}_{\mathrm{E}}$, and $\mathrm{P}_{\mathrm{ETCO}_{2}}$ During Sleep Stages 2 and 3-4 During PSV in the 10 Patients With Central Apneas

\begin{tabular}{|c|c|c|c|}
\hline & Baseline & $\begin{array}{l}\text { Pre-Apneas } \\
\text { PSV }\end{array}$ & $P$ \\
\hline \multicolumn{4}{|l|}{$\mathrm{V}_{\mathrm{T}}, \mathrm{mL}$} \\
\hline Stage 2 & $440 \pm 63$ & $623 \pm 62$ & .001 \\
\hline Stage 3-4 & $425 \pm 67$ & $585 \pm 70$ & .001 \\
\hline \multicolumn{4}{|c|}{$\mathrm{f}$, breaths/min } \\
\hline Stage 2 & $17 \pm 3$ & $16 \pm 4$ & .16 \\
\hline Stage 3-4 & $13 \pm 3$ & $12 \pm 1$ & .23 \\
\hline \multicolumn{4}{|l|}{$\dot{\mathrm{V}}_{\mathrm{E}}, \mathrm{L} / \mathrm{min}$} \\
\hline Stage 2 & $7.5 \pm 0.5$ & $9.7 \pm 0.5$ & .001 \\
\hline Stage $3-4$ & $5.2 \pm 0.5$ & $6.8 \pm 0.8$ & .001 \\
\hline \multicolumn{4}{|c|}{$\mathrm{P}_{\mathrm{ETCO}_{2}}, \mathrm{~mm} \mathrm{Hg}$} \\
\hline Stage 2 & $41 \pm 3.5$ & $36 \pm 2.9$ & .001 \\
\hline Stage 3-4 & $46 \pm 1.4$ & $42 \pm 1.0$ & .001 \\
\hline \multicolumn{4}{|c|}{$\begin{array}{l}\text { Values are mean } \pm \mathrm{SD} \\
\mathrm{V}_{\mathrm{T}}=\text { tidal volume } \\
\mathrm{f}=\text { breathing frequency } \\
\dot{\mathrm{V}}_{\mathrm{E}}=\text { minute ventilation } \\
\mathrm{P}_{\mathrm{E}_{\mathrm{TCO}}}=\text { end-tidal } \mathrm{P}_{\mathrm{CO}_{2}} \\
\mathrm{PSV}_{2} \text { pressure support ventilation }\end{array}$} \\
\hline
\end{tabular}

Table 4. $\quad \mathrm{V}_{\mathrm{T}}$, f-flow, and EAdi Peak Variability in the 10 Patients With Central Apneas

\begin{tabular}{|c|c|c|c|}
\hline & \multicolumn{2}{|c|}{ Coefficient of Variation $\%$} & \multirow[b]{2}{*}{$P$} \\
\hline & PSV & NAVA & \\
\hline \multicolumn{4}{|c|}{$\mathrm{V}_{\mathrm{T}}$} \\
\hline Stage 1 & $9.5 \pm 6.2$ & $16.6 \pm 12.3$ & .001 \\
\hline Stage 2 & $7.4 \pm 5.3$ & $17.8 \pm 11.4$ & .001 \\
\hline Stage 3-4 & $6.6 \pm 5.7$ & $17.3 \pm 8.9$ & .001 \\
\hline REM & $9.8 \pm 5.9$ & $16.9 \pm 10.6$ & .001 \\
\hline \multicolumn{4}{|l|}{ f-flow } \\
\hline Stage 1 & $13.3 \pm 5.8$ & $21.4 \pm 11.4$ & .008 \\
\hline Stage 2 & $15.8 \pm 7.6$ & $17.6 \pm 10.5$ & .21 \\
\hline Stage $3-4$ & $21.6 \pm 10.5$ & $15.4 \pm 6.7$ & .002 \\
\hline REM & $14.8 \pm 8.6$ & $18.8 \pm 12.8$ & .009 \\
\hline \multicolumn{4}{|l|}{ EAdi $_{\text {peak }}$} \\
\hline Stage 1 & $25.5 \pm 9.7$ & $23.8 \pm 7.8$ & .049 \\
\hline Stage 2 & $32.8 \pm 12.6$ & $21.7 \pm 6.8$ & .002 \\
\hline Stage $3-4$ & $41.3 \pm 20.2$ & $24.2 \pm 8.8$ & .008 \\
\hline REM & $24.6 \pm 7.1$ & $24.3 \pm 8.4$ & .69 \\
\hline $\begin{array}{l}V_{\mathrm{T}}=\text { tidal volum } \\
\text { f-flow }=\text { flow ba } \\
\text { EAdi peak = peak } \\
\text { PSV = pressure } \\
\text { NAVA = Neurall } \\
\text { REM }=\text { rapid eye }\end{array}$ & $\begin{array}{l}\text { ng frequency } \\
\text { ictivity of the diaph } \\
\text { tilation } \\
\text { Ventilatory Assis } \\
\text { it }\end{array}$ & & \\
\hline
\end{tabular}

NAVA during all sleep stages, indicating increased breathto-breath variability, compared to PSV. In PSV mode, $\mathrm{V}_{\mathrm{T}}$ variability differed significantly between stage 1 and stage 3-4 sleep, but not between stage 1 and REM sleep 


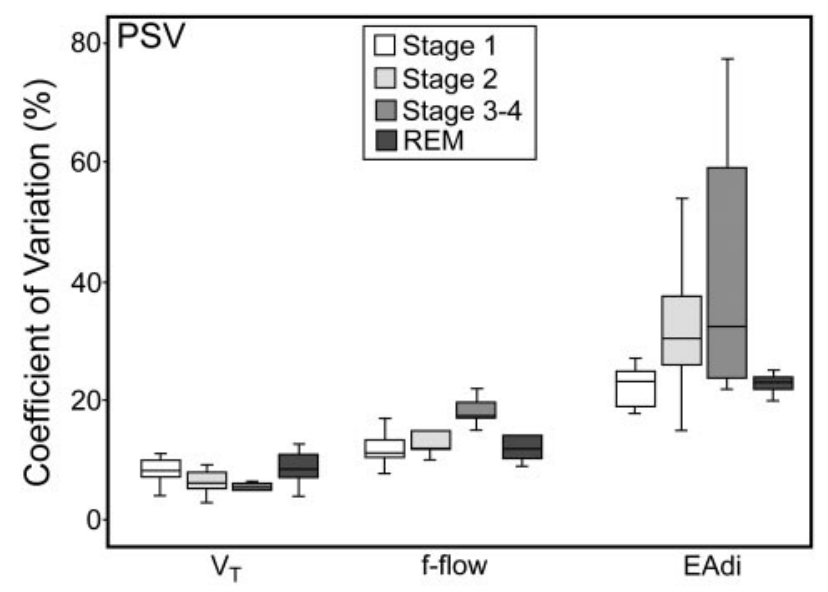

Fig. 3. Variability during pressure support ventilation (PSV). $\mathrm{V}_{\mathrm{T}}=$ tidal volume. f-flow $=$ flow-based breathing frequency. EAdi $=$ electrical activity of the diaphragm.

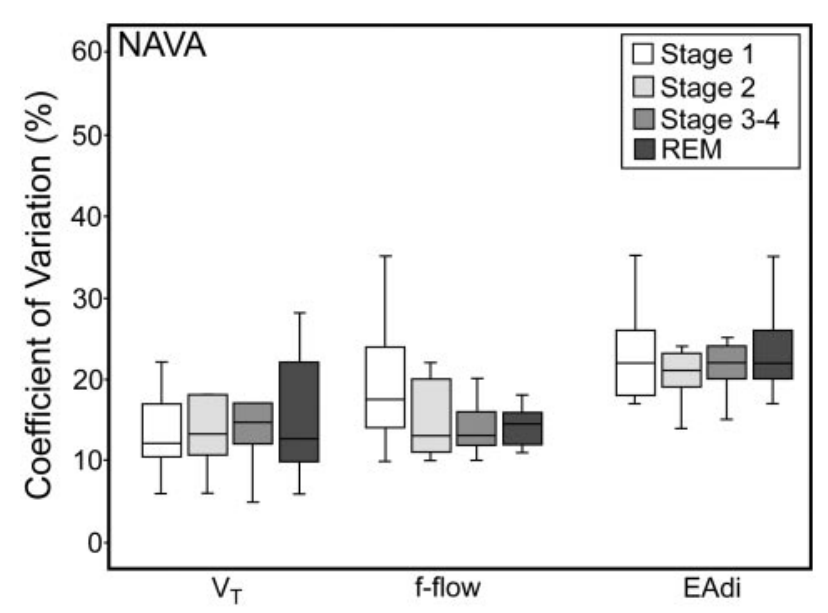

Fig. 4. Variability during neurally adjusted ventilatory assist (NAVA). $V_{T}=$ tidal volume f-flow $=$ flow-based breathing frequency. EAdi $=$ electrical activity of the diaphragm.

$(P=.14) . \mathrm{V}_{\mathrm{T}}$ variability during stage 2 and stage $3-4$ sleep in PSV mode differed significantly from that in REM sleep ( $P=.01$ and $P=.001$, respectively) (Fig. 3). With NAVA, $V_{\mathrm{T}}$ variability was stable, with no significant differences across sleep stages (Fig. 4). Tidal volume variability was significantly greater with NAVA than with PSV (17.2 \pm 8 vs $10.3 \pm 4, P=.045)$.

With PSV, f-flow variability differed significantly between sleep stages 1 and 3-4 $(P=.01), 2$ and $3-4$ $(P=.005)$, and 3-4 and REM $(P=.001)$ (see Fig. 3). With NAVA, f-flow variability showed no significant differences across sleep stages (see Fig. 4).

With PSV, peak EAdi variability differed significantly between sleep stages 1 and $2(P=.005), 1$ and 3-4 $(P=.003), 2$ and REM $(P=.038)$, and $3-4$ and REM
$(P=.002)$ (see Fig. 3). With NAVA, peak EAdi variability did not vary significantly across sleep stages (see Fig. 4).

\section{Discussion}

In this study of unsedated subjects responding to simple orders when awake and receiving assisted mechanical ventilation during the weaning process, the occurrence of central apneas was influenced by the ventilatory mode. Sleep disruption is common in critically ill patients and may influence the clinical course of the acute illness. ${ }^{8,34,35}$ Even if it is well documented that sleep abnormalities may impair psychological and physiological well-being, with effects such as increased protein catabolism, decreased immune function, and altered respiratory mechanics, which could affect weaning from mechanical ventilation, ${ }^{36}$ the impact of sleep disturbances on morbidity and mortality remains unknown ${ }^{37}$; however, it could worsen the quality of life after discharge. ${ }^{38,39}$

Quantitative and qualitative deficiencies have been characterized, including decreased total sleep time, fragmented sleep, as well as altered circadian patterns. The etiology of sleep disruption in the ICU is multifactorial, including the inherent nature of environment (exposure to noise and light), medications, mechanical ventilation, and particularly, patient-ventilator interaction and acute illness. PSV is associated with central apneas in both healthy individuals ${ }^{1}$ and mechanically ventilated patients, ${ }^{40}$ and the ventilator settings influence the degree of sleep disruption, ${ }^{41}$ suggesting that patient-ventilator asynchrony may contribute to sleep disruption. ${ }^{42}$ Studies have established that decreasing patient-ventilator asynchrony results in less sleep disruption and in greater sleep efficiency. ${ }^{43,44}$ Proportional assist ventilation and NAVA were developed to better match the level of assistance delivered by the ventilator to the needs of the individual patient, thereby minimizing patient-ventilator asynchrony. ${ }^{10}$

NAVA is an assist mode in which the ventilator is triggered, even during expiration with intrinsic PEEP, and cycled off based on the EAdi value, which directly reflects the activity of the patient's neural respiratory command. ${ }^{11}$ The inspiratory airway pressure applied by the ventilator is determined as follows:

$$
\mathrm{P}_{\mathrm{aw}}=\text { NAVA level } \times \text { EAdi }
$$

where $\mathrm{P}_{\mathrm{aw}}$ is the instantaneous airway pressure $\left(\mathrm{cm} \mathrm{H}_{2} \mathrm{O}\right)$, EAdi is the instantaneous integral of the diaphragmatic electrical activity signal $(\mu \mathrm{V})$, and NAVA level ( $\mathrm{cm} \mathrm{H}_{2} \mathrm{O} / \mu \mathrm{V}$ or per arbitrary unit) is a proportionality constant set by the clinician. NAVA does not depend on measurements of airway pressure or flow, and keeps the assist synchronized with the inspiratory efforts (indepen- 
dently from leaks or intrinsic PEEP). ${ }^{12,14,15,45-47}$ Thus, the delivered pressure is, in theory, synchronous with the diaphragmatic activity, and $\mathrm{V}_{\mathrm{T}}$ is completely controlled by the output of the patient's neural respiratory command center. ${ }^{11}$ In contrast to PSV, NAVA prevents excessive $\mathrm{P}_{\mathrm{aw}}$ and $\mathrm{V}_{\mathrm{T}}$ values, because EAdi undergoes down-regulation in response to increasing assistance levels, thereby decreasing the amount of assistance provided. 13,14,19,48,49

In a recent comparison of the impact of NAVA and PSV on sleep architecture, we demonstrated that NAVA provided better sleep quality in terms of REM sleep, fragmentation index, and ineffective efforts in unsedated adults. ${ }^{18}$ NAVA also allows considerable variability in the breathing pattern (ie, better replicates the variability of spontaneous breathing). We hypothesized that this greater variability, compared to PSV, decreased central apneas. To our knowledge, this hypothesis has not been evaluated previously. The greater ventilatory variability with NAVA is related to increased flow complexity, with no change in EAdi complexity, compared to PSV. ${ }^{16}$ The better coupling between mechanical assistance and neural output achieved with NAVA may result in better translation of the complexity of the central ventilatory command into a complex flow pattern. NAVA prevents over-assistance, thereby avoiding episodes of hyperventilation leading to central apneas.

In a polysomnography study of 11 critically ill patients, sleep fragmentation was less marked with continuous mandatory ventilation than with PSV, because PSV was associated with over-assistance-induced central apneas..$^{40}$ Overassistance was reflected by higher $\mathrm{V}_{\mathrm{T}}$ values during PSV than during continuous mandatory ventilation. Adding a mechanical dead space significantly decreased the number of central apneas: a finding that further supported overassistance as the cause of central apneas. ${ }^{40,50}$

A study comparing PSV and the SmartCare automated weaning system in conscious unsedated patients showed similar numbers of central apneas. ${ }^{51}$ SmartCare is an embedded version of the closed-loop NeoGanesh system, ${ }^{52,53}$ which keeps the patient within the comfort zone (as defined by respiratory parameters) while gradually decreasing the level of pressure support to a minimal value, at which point a trial of spontaneous breathing is performed. SmartCare would be expected to prevent over-assistance by adjusting the level of support. The absence of a difference in central apnea occurrence between PSV and SmartCare may be ascribable to the large proportion in this study ${ }^{51}$ of patients with chronic heart failure, a risk factor for central apneas. In our subjects also, central apneas occurred chiefly during non-REM sleep, possibly as a result of sequential over-assistance $\left(\mathrm{V}_{\mathrm{T}}\right.$ overshoot $)$, which is seen with PSV but not with NAVA. The mechanisms underlying central apneas may be too complex to be prevented by closed-loop mechanical ventilation. Proportional ventilation seems crucial to preventing central apneas. How- ever, the concept underlying SmartCare is interesting, and studies comparing NAVA and SmartCare are needed. In our study the ventilatory behavior preceding central apneas with PSV was similar to that described in a previous study. ${ }^{3}$ Another finding shared by both studies is the increase in $\mathrm{V}_{\mathrm{T}}$ and $\dot{\mathrm{V}}_{\mathrm{E}}$ immediately before central apneas, together with a $\mathrm{P}_{\mathrm{ETCO}_{2}}$ to the apneic threshold. ${ }^{3}$

A few methodological points deserve discussion. We obtained 4-hour long recordings on 4 different occasions in each subject. Each subject was studied for 24 consecutive hours. This method was chosen to minimize instabilities or complications, and to avoid delays in extubation. Cessation of sedatives for more than 24 hours does not rule out residual sedation. However, all subjects had Ramsay scores no greater than 2 and Glasgow Coma Scale scores of 11 or more at the time of recording. ${ }^{51}$ Subjects with risk factors for central apnea (chronic heart failure or COPD) had more numerous central apneas during non-REM sleep, suggesting lower apnea $\mathrm{P}_{\mathrm{aCO}}$ thresholds for central apnea.

Increased diaphragmatic activity during non-REM sleep is associated with an increase in $\mathrm{V}_{\mathrm{T}} \cdot{ }^{54} \mathrm{In}$ our study, subjects receiving PSV exhibited increased peak EAdi variability during non-REM sleep and a concomitant $\mathrm{V}_{\mathrm{T}}$ increase, with little $\mathrm{V}_{\mathrm{T}}$ variability. This pattern increases the risk of central apnea, especially as the apneic threshold is lower in REM sleep than in non-REM sleep. ${ }^{55}$

A study in healthy volunteers showed suppression of tonic diaphragmatic activity, with preservation of phasic activity during REM sleep. ${ }^{56}$ Transition inhibition of the intercostal muscles is abolished and phasic activity of the intercostal, abdominal, and sternocleidomastoid muscles is greatly reduced. ${ }^{56,57}$ The contribution of rib cage motion to $\mathrm{V}_{\mathrm{T}}$ is moderate during REM sleep, and as a result, $\mathrm{V}_{\mathrm{T}}$ decreases significantly with NAVA, but not with PSV. Moreover $\mathrm{V}_{\mathrm{T}}$ variability is higher, which may protect against central apnea.

Limitations of our study should be acknowledged. First, this work was performed in a single center with researcher experience on NAVA, and included only 14 subjects. Therefore, these results may not pertain to other ICUs and to all subjects. Second, sedation was stopped only 24 hours before beginning the study, so we could not exclude that there was an effect of sedation. However, all subjects included experienced NAVA and PSV alternately. Third, a single NAVA level and PSV were used, but we could not be certain that the results were the same with another level. Nevertheless our study demonstrated a physiological effect of NAVA, which must be confirmed by further clinical studies.

\section{Conclusions}

To our knowledge, this study provides the first comparative data on the occurrence of central apneas with PSV 


\section{Effect of Ventilatory Variability on Occurrence of Central Apneas}

and NAVA in unsedated, ventilated, critically ill subjects. At a constant ventilation level, NAVA was associated with greater ventilatory variability than PSV. With PSV, overassistance $\left(\mathrm{V}_{\mathrm{T}}\right.$ overshoot) occurred in sleep stages 2 and 3-4. Central apneas occurred only with PSV. The absence of central apneas with NAVA was probably ascribable to improvements in neuromechanical coupling, which avoided the delivery of excessive assistance. The protective effect of NAVA against central apneas occurred even in patients with risk factors (chronic heart failure or COPD). Our data support the use of NAVA in novel ventilation strategies, particularly in patients at risk for central apnea. However, further clinical investigations are needed to evaluate the impact of NAVA on weaning time and patient outcomes.

\section{ACKNOWLEDGMENT}

We are grateful to Hélène Prigent MD, Physiology and Functional Testing Department, Raymond Poincaré Teaching Hospital, Garches, France, for her help in editing the manuscript.

\section{REFERENCES}

1. Meza S, Mendez M, Ostrowski M, Younes M. Susceptibility to periodic breathing with assisted ventilation during sleep in normal subjects. J Appl Physiol 1998;85(5):1929-1940.

2. Dempsey JA, Smith CA, Przybylowski T, Channel B, Xie A, Nakayama $\mathrm{H}$, Skatrud JB. The ventilatory responsiveness to $\mathrm{CO}_{2}$ below eupnoea as a determinant of ventilatory stability in sleep. J Physiol 2004;560(Pt 1):1-11

3. Xie A, Skatrud JB, Dempsey JA. Effect of hypoxia on the hypopnoeic and apnoeic threshold for $\mathrm{CO}_{2}$ in sleeping humans. J Physiol 2001;535(Pt 1):269-275.

4. Gleeson K, Zwillich CW, White DP. The influence of increasing ventilator effort on arousal from sleep. Am Rev Respir Dis 1990; 142(2):295-300.

5. Kimoff RJ, Cheong TH, Olha AE, Charbonneau M, Levy RD, Cosio MG, Gottfried SB. Mechanisms of apnea termination in obstructive sleep apnea. Role of chemoreceptor and mechanoreceptor stimuli. Am J Respir Crit Care Med 1994;149(3 Pt 1):707-714.

6. Hanly P, Zuberi N, Gray R. Pathogenesis of Cheyne-Stokes respiration in patients with congestive heart failure. Relationship to arterial $\mathrm{P}_{\mathrm{CO}_{2}}$. Chest 1993;104(4):1079-1084.

7. Hanly PJ, Millar TW, Sleljes DG, Baert R, Frais MA, Kryger MH. Respiration and abnormal sleep in patients with congestive heart failure. Chest 1989;96(3):480-488.

8. Parthasarathy S, Tobin MJ. Sleep in the intensive care unit. Intensive Care Med 2004;30(2):197-206

9. Simmons LE, Riker RR, Prato BS, Fraser GL. Assessing sedation during intensive care unit mechanical ventilation with the Bispectral Index and Sedation-Agitation scale. Crit Care Med 1999;27(8):14991504.

10. Navalesi P, Costa R. New modes of mechanical ventilation: proportional assist ventilation, neurally adjusted ventilatory assist, and fractal ventilation. Curr Opin Crit Care 2003;9(1):51-58.

11. Sinderby C, Navalesi P, Beck J, Skrobick Y, Comtois N, Friberg S, et al. Neural control of mechanical ventilation in respiratory failure. Nat Med 1999;5(12):1433-1436

12. Terzi N, Pelieu I, Guillet L, Ramakers M, Seguin A, Daubin C, et al. Neurally adjusted ventilatory assist in patients recovering spontaneous breathing after acute respiratory distress syndrome: physiological evaluation. Crit Care Med 2010;38(9):1830-1837.
13. Brander L, Leong-Poi H, Beck J, Brunet F, Hutchison SJ, Slutsky AS, Sinderby C. Titration and implementation of neurally adjusted ventilatory assist in critically ill patients. Chest 2009;135(3):695703.

14. Colombo D, Cammarota G, Bergamaschi V, De Lucia M, Corte FD, Navalesi P. Physiologic response to varying levels of pressure support and neurally adjusted ventilatory assist in patients with acute respiratory failure. Intensive Care Med 2008;34(11):2010-2018.

15. Spahija J, de Marchie M, Albert M, Bellemare P, Delisle S, Beck J, Sinderby C. Patient-ventilator interaction during pressure support ventilation and neurally adjusted ventilatory assist. Crit Care Med 2010;38(2):518-526.

16. Schmidt M, Demoule A, Cracco C, Gharbi A, Fiamma MN, Straus $\mathrm{C}$, et al. Neurally adjusted ventilatory assist increases respiratory variability and complexity in acute respiratory failure. Anaesthesiology 2010;112(3):670-681.

17. Croisel Y, Chanques G, Jung B, Constantin JM, Capdevila X, Matecki S, et al. Neurally adjusted ventilatory assist in critically ill postoperative patients: a crossover randomized study. Anesthesiology 2010;113(4):925-935.

18. Delisle S, Ouellet P, Bellemare P, Tétrault JP, Arsenault P. Sleep quality in mechanically ventilated patients: comparison between NAVA and PSV modes. Ann Intensive Care 2011;1(1):42.

19. Sinderby C, Beck J, Spahija J, de Marchie M, Lacroix J, Navalesi P, Slutsky AS. Inspiratory muscle unloading by neurally adjusted ventilatory assist during maximal inspiratory efforts in healthy subjects. Chest 2007;131(3):711-717

20. Jasper HH. The ten twenty electrode system of the International Federation. Electroencephalgr Clin Neurophysiol 1958;10:371-375

21. Rechtschaffen A, Kales A. Manual of standardized terminology, techniques and scoring system for sleep stages of human subjects. Los Angeles: UCLA BIS/BRI; 1968.

22. Atlas Task Force of the American Sleep Disorders Association. EEG arousals: scoring rules and examples. A preliminary report from the Sleep Disorders Atlas Task Force of the American Sleep Disorders Association. Sleep 1992;15(2):173-184.

23. American Academy of Sleep Medicine Task Force. Sleep-related breathing disorders in adults: recommendation for syndrome definition and measurement techniques in clinical research. Sleep 1999; 22(5):667-689.

24. Xie A, Wong B, Phillipson EA, Slutsky AS, Bradley TD. Interaction of hyperventilation and arousal in the pathogenesis of idiopathic central sleep apnea. Am J respire Crit Care Med 1994;150(2):489495

25. Trinder J, Merson R, Rosenberg JI, Fitzqerald F, Kleiman J, Bradley TD. Pathophysiological interactions of ventilation, arousals, and blood pressure oscillations during Cheynes-Stokes respiration in patients with heart failure. Am J Respir Crit Care Med 2000;162(3 Pt 1): 808-813.

26. Spahija J, Beck J, Lindström L, Bégin P, de Marchie M, Sinderby C. Effect of increased diaphragm activation on diaphragm power spectrum center frequency. Respir Physiol Neurobiol 2005;146(1):67-76.

27. Sinderby C, Lindström L, Grassino AE. Automatic assessment of electromyogram quality. J Appl Physiol 1995;79(5):1803-1815.

28. Sinderby C, Beck J, Spahija J, Weinberg J, Grassino A. Voluntary activation of the human diaphragm in health and disease. J Appl Physiol 1998;85(6):2146-2158.

29. Beck J, Sinderby C, Weinberg J, Grassino A. Effects of muscle-toelectrode distance on the human diaphragm electromyogram. J Appl Physiol 1995;79(3):975-985.

30. Beck J, Sinderby C, Lindström L, Grassino A. Influence of bipolar esophageal electrode positioning on measurements of human crural diaphragm electromyogram. J Appl Physiol 1996;81(3):1434-1449. 


\section{Effect of Ventilatory Variability on Occurrence of Central Apneas}

31. Sinderby CA, Beck JC, Lindström LH, Grassino AE. Enhancement of signal quality in esophageal recordings of diaphragm EMG. J Appl Physiol 1997;82(4):1370-1377.

32. Tobin MJ, Mador MJ, Guenther SM, Lodato RF, Sackner MA. Variability of resting respiratory drive and timing in healthy subjects. J Appl Physiol 1988;65(1):309-317.

33. Wrigge H, Golisch W, Zinserling J, Sydow M, Almeling G, Burchardi H. Proportional assist versus pressure support ventilation: effects on breathing pattern and respiratory work of patients with chronic obstructive pulmonary disease. Intensive Care Med 1999; 25(8):790-798.

34. Parthasarathy S. Sleep during mechanical ventilation. Curr Opin Pulm Med 2004;10(6):489-494.

35. Krachman SL, D'Alonzo GE, Crimer GJ. Sleep in the intensive care unit. Chest 1995;107(6):1713-1720.

36. Weinhouse GL, Schwab RJ. Sleep in the critically ill patient. Sleep 2006;29(5):707-716.

37. Drouot X, Cabello B, d'Ortho MP, Brochard L. Sleep in the intensive care unit. Sleep Med Rev 2008;12(5):391-403.

38. Weinhouse GL, Schwab RJ, Watson PL, Patil N, Vaccaro B, Pandharipande $\mathrm{P}$, et al. Bench-to-bedside review: delirium in ICU patients: importance of sleep deprivation. Crit Care 2009;13(6):234.

39. Friese RS, Diaz-Arrastia R, McBride D, Frankel H, Gentilello LM. Quantity and quality of sleep in the surgical intensive care unit: are our patients sleeping? J Trauma 2007;63(6):1210-1214.

40. Parthasarathy S, Tobin MJ. Effect of ventilator mode on sleep quality in critically ill patients. Am J Respir Crit Care Med 2002;166(11): 1423-1429.

41. Fanfulla F, Delmastro M, Berardinelli A, Lupo ND, Nava S. Effects of different ventilator settings on sleep and inspiratory effort in patients with neuromuscular disease. Am J Respir Crit Care Med 2005; 172(5):619-624

42. Gabor JY, Cooper AB, Hanly PJ. Sleep disruption in the intensive care unit. Curr Opin Crit Care 2001;7(1):21-27.

43. Bosma K, Ferreyra G, Ambrogio C, Pasero D, Mirabella L, Braghiroli A, et al. Patient-ventilator interaction and sleep in mechanically ventilated patients: pressure support versus proportional assist ventilation. Crit Care Med 2007;35(4):1048-1054.

44. Alexopoulou C, Kondili E, Vakouti E, Klimathianaki M, Prinianakis $\mathrm{G}$, Georgopoulos D. Sleep during proportional-assist ventilation with load-adjustable gain factors in critically ill patients. Intensive Care Med 2007;33(7):1139-1147.

45. Moerer O, Beck J, Brander L, Costa R, Quinte M, Slutsky AS, et al. Subject-ventilator synchrony during neural versus pneumatically trig- gered non-invasive helmet ventilation. Intensive Care Med 2008; 34(9):1615-1623.

46. Beck J, Reilly M, Grasselli G, Mirabella L, Stutsky AS, Dunn MS, Sinderby C. Patient-ventilator interaction during neurally adjusted ventilatory assist in low birth weight infants. Pediatr Res 2009;65(6): 663-668.

47. Wu XY, Huang YZ, Yang Y, Liu SQ, Liu HG, Qiu HB. Effects of neurally adjusted ventilatory assist on patient-ventilator synchrony in patients with acute respiratory distress syndrome. Zhonghua Jie He He Hu Xi Za Zhi 2009;32(7):508-512. Article in Chinese.

48. Allo JC, Beck JC, Brander L, Brunet F, Slutsky AS, Sinderby CA. Influence of neurally adjusted ventilatory assist and positive endexpiratory pressure on breathing pattern in rabbits with acute lung injury. Crit Care Med 2006;34(12):2997-3004.

49. Brander L, Sinderby C, Lecompte F, Leon-Poi H, Bell D, Beck J, et al. Neurally adjusted ventilatory assist decreases ventilator-induced lung injury and non-pulmonary organ dysfunction in rabbits with acute lung injury. Intensive Care Med 2009;35(11):1979-1989.

50. Toublanc B, Rose D, Glerant JC, Francois G, Mayeux I, Rodenstein D, Jounieaux V. Assist-control ventilation vs low levels of pressure support ventilation on sleep quality in intubated ICU patients. Intensive Care Med 2007;33(7):1148-1154.

51. Cabello B, Thille AW, Drouot X, Galia F, Mancebo J d'Ortho MP, Brochard L. Sleep quality in mechanically ventilated patients: comparison of three ventilatory modes. Crit Care Med 2008;36(6):17491755.

52. Dojat M, Harf A, Touchard D, Lemaire F, Brochard L. Clinical evaluation of a computer-controlled pressure support mode. Am J Respir Crit Care Med 2000;161(4 Pt 1):1161-1166.

53. MacIntyre NR. Respiratory function during pressure support ventilation. Chest 1986;89(5):677-683.

54. Lopes JM, Tabachnik E, Muller NL, Levison H, Bryan AC. Total airway resistance and respiratory muscle activity during sleep. J Appl Physiol 1983;54(3):773-777.

55. Douglas NJ, White DP, Weil JV, Pickett CK, Zwillich CW. Hypercapnic ventilatory response in sleeping adults. Am Rev Resp Dis 1982;126(5):758-762.

56. Tusiewicz K, Moldofsky H, Bryan AC, Bryan MH. Mechanics of the ribcage and diaphragm during sleep. J Appl Physiol 1977;43(4):600602

57. Tabachnik E, Muller NL, Bryan AC, Levison H. Changes in ventilation and chest wall mechanics during sleep in normal adolescents. J Appl Physiol 1981;51(3):557-564.

This article is approved for Continuing Respiratory Care Education credit. For information and to obtain your CRCE

(free to AARC members) visit www.rcjournal.com 